\title{
A AVALIAÇÃO DE COMPETIÇÕES ESPORTIVAS DE JOVENS: DEFINIÇÃO DE CATEGORIAS E APLICAÇÕES AO HANDEBOL
}

\author{
YOUTH SPORTS COMPETITIONS EVALUATION: DEFINITION OF CATEGORIES \\ AND APPLICATIONS TO HANDBALL
}

\section{LA EVALUACIÓN DE COMPETICIONES DEPORTIVAS JUVENILES: DEFINICIÓN DE CATEGORÍAS Y APLICACIONES AL BALONMANO}

\author{
Lucas Leonardo*, Alcides José Scaglia**
}

Palavras chave: Aprendizagem. Jovens.

Esportes.

\begin{abstract}
Resumo: Competições esportivas de jovens devem ser elaboradas com metas distintas dos cenários competitivos orientados aos adultos, contribuindo com o processo de ensinoaprendizagem esportivo. $\mathrm{O}$ objetivo deste estudo foi formular uma proposta avaliativa para competições que permita verificar sua adequação às necessidades do público jovem. Baseados em estudos sobre programas esportivos e competitivos de jovens, estabelecemos critérios de avaliação aplicados a três competições de handebol de jovens realizadas no estado de São Paulo, Brasil. Notamos que a Liga de Handebol do Estado de São Paulo e a Federação Paulista de Handebol destoam de ambientes ajustados aos jovens e que a Liga de Desenvolvimento do Handebol Paulista se alinha aos pressupostos defendidos pela base teórica desta investigação. Ainda, o compromisso esperado pelos treinadores para que atletas participem das competições se afasta das metas competitivas modificadas ao jovem, assim, a influência do treinador pode subverter as propostas destes cenários.
\end{abstract}

\begin{abstract}
Youth sports competitions' goals should be different from adult-oriented competitive scenarios in order to contribute to the process of teaching and learning sports. This study presents an evaluative proposal for youth competitions to verify their suitability to the needs of young people. Based on studies about sports and competitive youth programs, we established evaluation criteria applied to three youth handball competitions held in the state of São Paulo, Brazil. We note that the São Paulo State Handball League and the São Paulo State Handball Federation are not youth-friendly environments and that the São Paulo Handball Development League is aligned with the assumptions advocated by the theoretical basis of this investigation. Furthermore, the commitment expected by coaches to allow their athletes to participate in competitions is not in line with competitive goals modified for youth. Therefore, coaches' influence may subvert the proposals of these scenarios.
\end{abstract}

Keywords:

Learning

Youth.

Sports.
Palabras clave: Aprendizaje.

Jóvenes.

Deportes.
Resumen: Competiciones deportivas juveniles deben ser elaboradas con metas distintas de los escenarios competitivos orientados a los adultos, contribuyendo con el proceso de enseñanza-aprendizaje deportivo. Este estudio formula una propuesta evaluativa para competiciones que permita verificar su adecuación a las necesidades del público joven. Basados en estudios sobre programas deportivos y competitivos de jóvenes, establecimos criterios de evaluación aplicados a tres competiciones de balonmano realizadas en São Paulo, Brasil. Notamos que la Liga de Balonmano do Estado de San Pablo y la Federación Paulista de Balonmano desatan de ambientes ajustados a los jóvenes y que la Liga de Desarrollo del Balonmano Paulista se alinea con los presupuestos defendidos por la base teórica de esta investigación. Además, el compromiso esperado por los entrenadores para que los atletas participen en las competiciones se aleja de las metas competitivas modificadas al joven, así, la influencia del entrenador puede subvertir las propuestas de estos escenarios.
*Universidade Estadual de Campinas. Campinas, SP, Brasil.

E-mail: lucasleo@gmail.com

**Universidade Estadual de Campinas. Limeira, SP, Brasil.

E-mail: alcides.scaglia@gmail.com

Recebido em: 06-06-2018 Aprovado em: 25-07-2018

DOI: https://doi.org/10.22456/1982-8918.83620 (c) (1) () Licence 


\section{INTRODUÇÃO}

As competições esportivas de jovens devem ser elaboradas com metas distintas dos cenários competitivos orientados aos adultos, assentando-se em seu caráter pedagógico e sobrepujando tendências como a especialização precoce, que pode levar ao elevado desgaste dos jovens expostos à sobrecarga emocional e física, desencadeando situações de abandono da prática esportiva (CHOI; JOHNSON; KIM, 2014; CÔTÉ; BAKER; ABERNETHY, 2007; DREWE, 1998; FRASER-THOMAS; CÔTÉ, 2006; LLOYD; OLIVER, 2012).

Para superar esse paradigma, um grande desafio se apresenta: sem negar a importância da competitividade, uma característica indissociável à prática esportiva, mudanças devem ser propostas para que a competição seja convertida num cenário de prática positiva que fomente o engajamento permanente do jovem na prática esportiva (BURTON; GILLHAM; HAMMERMEISTER, 2011; CRANE; TEMPLE, 2015).

A competição de jovens deve caminhar em consonância ao processo de ensino, vivência e aprendizagem esportiva e estar alicerçada em princípios pedagógicos ajustados às necessidades, possibilidades e demandas do jovem, elevando a competição a um ambiente de aprendizagem pautado no jogo e que deve ser mediado pelo treinador (LEONARDO; GALATTI; SCAGLIA, 2017; REVERDITO et al., 2008; SCAGLIA et al., 2013). Assim, competir poderá colaborar para o desenvolvimento de distintas competências, como as aprendizagens táticotécnica, psicológica e moral, fazendo do esporte um fenômeno cujos valores serão levados para toda a vida (BERGERON et al., 2015; CÔTÉ; BAKER; ABERNETHY, 2007; ENGEBRETSEN et al., 2010; GONÇALVES; CARVALHO; LIGHT, 2011; MOUNTJOY et al., 2008).

\section{BASE TEÓRICA}

Para tanto, torna-se fundamental conhecer propostas sustentadas em evidências que balizem esta transformação e que possibilitem a análise objetiva sobre a coerência interna destes cenários quando aplicados os jovens. Neste sentido, Côté (1999), Wiersma (2005), Burton, Gillham e Hammermeister (2011) e Côté e Hancock (2016) apresentam em suas obras orientações que estabelecem íntimas interrelações entre si, e que possibilitam a elaboração de um quadro teórico norteador para a promoção de competições ajustadas ao público jovem.

Em sua obra, Wiersma (2005) defende um sistema de classificação das competições em quatro níveis distintos. O primeiro nível caracteriza-se pela ausência da competição formal, viagens e tabelas de classificação. Em consonância com a Engenharia Competitiva de Burton, Gillham e Hammermeister (2011), neste nível competitivo modificam-se os equipamentos e as instalações em função de baixos níveis de habilidade dos praticantes, garantindo que crianças joguem em tempos iguais devido às mudanças das regras da competição.

O segundo nível, ainda com baixos níveis de competitividade, já pode ser organizado em formato de ligas, com presença de placares, tabelas e resultados. A competição deve acontecer em local centralizado para facilitar o acesso das equipes próximas, reduzindo deslocamentos para realização dos jogos, tornando a prática mais barata e menos elitizada, como destacam Côté e Hancock (2016) no estudo "Políticas baseadas em evidências para programas esportivos de jovens". Também deve haver paridade competitiva entre as equipes com o equilíbrio das partidas, visando minimizar a ocorrência de placares com largas margens 
de pontuação, aspecto que, segundo Burton, Gillham e Hammermeister (2011), pode desencadear experiências negativas aos derrotados.

Esses dois níveis, quando analisados à luz do Modelo de Desenvolvimento e Participação Esportiva (MDPE) (CÔTÉ, 1999), configuram-se como competições coerentes com as fases de experimentação (até os 12 anos de idade) e especialização (dos 13 aos 15 anos de idade), períodos nos quais a especialização esportiva deve ser evitada por meio de variada oferta de ambientes de aprendizagem sustentados pelo jogo mediado pelo treinador.

No terceiro nível há a ênfase aos atletas de maiores habilidades. A temporada competitiva torna-se mais ampla, pois se espera maior compromisso dos jovens atletas com a prática esportiva. Serão frequentes as viagens e a seleção de atletas para participação dos jogos. Já no quarto nível espera-se compromisso em competições anuais que serão mais caras se comparados aos níveis anteriores. Haverá restrição aos atletas em relação à participação em outros esportes e atividades extracurriculares, pois já se prioriza a conquista de resultados competitivos. Aumenta-se, assim, a intensidade e exigência nos treinamentos e espera-se que os atletas já possuam grande experiência anterior com a prática esportiva.

De acordo com Côté (1999), competições com demandas semelhantes aos níveis três e quatro propostos por Wiersma (2005) associam-se ao período de investimento esportivo (a partir dos 16 anos de idade), no qual o direcionamento para a prática esportiva especializada, próxima aos modelos de alto rendimento, torna-se uma realidade.

\section{A AVALIAÇÃO DO AMBIENTE COMPETITIVO}

A partir da base teórica apresentada, entendemos que competições de jovens podem ser elaboradas com distintas perspectivas e metas. Enquanto algumas competições tendem a se aproximar mais das necessidades do jovem, orientando-se para a aprendizagem, outras podem se afastar dessa perspectiva, por se sustentarem em valores tradicionais do esporte, orientando-se para a via exclusiva da performance.

Segundo Wiersma (2005), as diferentes metas de contextos competitivos como esses devem ser claramente divulgadas aos participantes, familiares e torcedores, conscientizandoos dos objetivos que sustentam a competição. A preocupação relatada pelo autor assentase na necessidade de que haja um alinhamento prévio entre as expectativas dos adultos em relação às metas competitivas traçadas em função das crianças e jovens, evitando distorções de comportamentos que possam influenciar de maneira contraditória o clima competitivo esperado.

Porém, será que os organizadores de programas esportivos de jovens têm conhecimento de que competições podem ser ofertadas em distintos níveis? São reconhecidas intencionalmente metas que vão além da tradicional finalidade centrada nos resultados competitivos? Como esclarecer torcedores, familiares e treinadores sobre essas metas quando elas podem não estar claramente definidas?

Para isso, torna-se necessário estabelecer critérios que sirvam tanto para avaliar o modelo competitivo ofertado como para orientar a elaboração crítica e consciente desses ambientes, tornando mais concretas suas características e permitindo que evidências mostrem se essas competições se aproximam ou se afastam de metas pedagógicas pretendidas ao público jovem. 
Diante deste cenário, este estudo buscou formular um instrumento de avaliação do nível competitivo para competições de jovens sustentado na base teórica e nos problemas descritos até o momento. Apresentaremos adiante os processos analíticos que nos permitiram definir as categorias, subcategorias e critérios avaliativos e as implicações práticas deste instrumento. Esperamos com este estudo instrumentalizar novas investigações em pedagogia do esporte e ajudar professores, treinadores e entidades de prática esportiva a terem um olhar mais atento e crítico à promoção e elaboração de ambientes competitivos ao público jovem.

\section{CAMINHOS METODOLÓGICOS}

Esta pesquisa é parte de um projeto aprovado pelo Comitê de Ética em Pesquisa sob o número 57799916.1.0000.5404, possui natureza quanti-qualitativa e caráter descritivoexploratório (YIN, 2016) e foi realizada por meio da definição de critérios avaliativos para análise do grau de adequação de competição de jovens às necessidades, demandas e possibilidades deste público.

Com a finalidade de demonstrar sua aplicabilidade, apresentaremos as implicações práticas resultantes da análise do grau de adequação de competições de handebol de jovens organizadas no estado de São Paulo, Brasil, no ano de 2017. A escolha das competições de handebol de jovens ocorreu por serem o objeto de estudos do projeto que engloba esta investigação, porém, por termos como base teórica estudos que tratam do papel do esporte de jovens num sentido amplo, consideramos o instrumento elaborado passível de aplicação em investigações sobre competições esportivas de jovens em diferentes modalidades esportivas.

Os procedimentos analíticos foram realizados a partir dos estudos de Côté (1999), Wiersma (2005), Burton, Gillham e Hammermeister (2011) e Côté e Hancock (2016) através da análise temática, um processo de análise de conteúdo que consiste em identificar os "núcleos de sentido" contidos nas unidades de contexto advindas da leitura dos materiais a serem analisados (BARDIN, 2016). Delimitamos como nosso corpus de pesquisa as orientações para a elaboração de competições de jovens presentes nesses estudos.

As unidades linguísticas normalizadas provenientes da análise temática comportaramse como os critérios de avaliação de nível competitivo de nosso instrumento de avaliação", cada um associado a um score que vai de um a quatro em função dos níveis competitivos definidos por Wiersma (2005). Esses critérios foram alocados em subcategorias, que foram alocadas numa categoria maior definida a priori a partir dos estudos que compõem nossa base teórica. As categorias são: 1) "Oferta de Competições"; 2) "Participação dos atletas na competição"; 3) "Compromisso Esperado" e 4) "Distância percorrida para jogar".

Para entender como as categorias, subcategorias e critérios de avaliação foram definidos, apresentaremos a seguir como cada estudo da base teórica contribuiu para a elaboração do instrumento de avaliação proposto.

\subsection{Categoria 1: oferta de competições}

Definimos a categoria "Oferta de Competições", na qual alocamos duas subcategorias: 1) "Número de Temporadas Competitivas". Para Wiersma (2005), as temporadas competitivas devem ser organizadas em festivais de um dia, podendo se estender entre três e quatro 
meses, chegando ao máximo de seis meses, segundo Côté e Hancock (2016), uma vez que temporadas longas exigem maior comprometimento e geram uma consequente tendência à especialização esportiva. A partir desses apontamentos, definimos quatro critérios de avaliação relativos aos quatro níveis competitivos propostos por Wiersma (2005) (ver Quadro 1). 2) "Modelo Competitivo". Para Wiersma (2005), nos níveis iniciais de competição deve ser evitada a eliminação das equipes, de modo a garantir que joguem a mesma quantidade de partidas durante a temporada, evitando sistemas de disputa excludentes típicos de competições tradicionais. Esses apontamentos nos permitiram alocar a essa subcategoria quatro critérios de avaliação relativos aos níveis competitivos propostos por Wiersma (2005) (ver Quadro 1).

\subsection{Categoria 2: participação dos atletas na competição}

Definimos nossa segunda categoria, "Participação dos atletas na competição", a partir dos apontamentos de Wiersma (2005), que defende a importância da participação dos jovens atletas em tempos iguais nas partidas, destacando ainda que em competições ajustadas às crianças deve haver o esforço para que os jogadores mais talentosos sejam distribuídos entre as equipes participantes. Burton, Gillham e Hammermeister (2011) complementam que a participação em tempos iguais nas partidas pode reforçar os sentimentos de competência, autonomia e bom relacionamento com o esporte. A partir dessas orientações, definimos quatro critérios de avaliação, apontados no Quadro 1, que se alinham aos níveis competitivos de Wiersma (2005).

\subsection{Categoria 3: compromisso esperado}

Na nossa terceira categoria, o "Compromisso Esperado", nos detivemos à obra de Côté (1999), na qual é abordado um relevante tema associado à importância da diversificação de estímulos esportivos durante a juventude, contrapondo os modelos de especialização precoce. Esse tema foi posteriormente transformado em postulados associados ao MDPE (CÔTÉ; LIDOR; HACKFORT, 2009), os quais afirmam que em esportes cujo pico de rendimento ocorre após o período maturacional, como os esportes coletivos de um modo geral, a diversificação de práticas esportivas tem implicações positivas no envolvimento esportivo em longo prazo e ao desenvolvimento positivo durante a juventude. Isso demonstra que a especialização em uma só prática esportiva não é o caminho indicado para o processo de formação esportiva.

Duas subcategorias representadas por duas questões foram alocadas à essa categoria. A primeira subcategoria tem como foco avaliar como os treinadores lidam com a participação dos atletas em atividades esportivas diferentes daquela em que o jovem compete regularmente, sendo representada pela pergunta: "Visando à participação na competição (com diferentes questionários para as distintas competições), como você lida com a participação de seus atletas em outras atividades esportivas?". A segunda subcategoria tem como foco avaliar o tempo semanal de dedicação para a prática do esporte em que o jovem compete regularmente, tendo em vista avaliar a proximidade ou o afastamento de tendências em relação à especialização precoce, e foi representada pela pergunta: "Visando à participação na competição (com diferentes questionários para as distintas competições), quantas horas semanais de treino são necessárias?". Para cada pergunta elaboramos opções de resposta em escala Likert associadas aos quatro níveis competitivos definidos por Wiersma (2005), conforme apresentado no Quadro 1. 


\subsection{Categoria 4: distância percorrida para jogar}

À nossa quarta categoria, "Distância percorrida para jogar", alocamos critérios de avaliação sustentados nas preocupações de Wiersma (2005) e Côté e Hancock (2016) no tocante à distância que o jovem percorre para participar de uma partida. Segundo Côté e Hancock (2016), distâncias excessivas para jogar são inadequadas para o público jovem, pois esse tipo de conduta demonstra um excessivo comprometimento do jovem com a prática esportiva num período em que a diversificação deve ser estimulada. Wiersma (2005) propõe que competições mais ajustadas aos jovens devem ser organizadas em modelos de festival e que as viagens sejam mais localizadas, garantindo a participação em competições mais centralizadas.

Por não haver parâmetros de referência na literatura, estabelecemos nossos critérios de avaliação a partir da análise das tabelas de jogos das três competições de handebol estudadas em nossas implicações práticas. A partir das distâncias entre as sedes dos jogos calculadas por georreferenciamento realizado no Google Maps (CAVICCHIOLI NETO et al., 2014) e levando em consideração a quantidade de jogos realizados pelas equipes em cada viagem, estabelecemos um índice médio com desvio padrão para as viagens das equipes em cada competição, o que permitiu que os resultados fossem apresentados com base em quatro critérios avaliativos, cada um deles associado a um nível competitivo proposto por Wiersma (2005) e retratado no Quadro 1.

Esta foi a única categoria na qual utilizamos como referência as informações das competições analisadas em nossas implicações práticas. Acreditamos que esta seja uma importante contribuição por serem evidências advindas da realidade competitiva de jovens e que podem ser utilizadas como referência para estudos realizados em outros contextos e com outras modalidades esportivas.

Todas essas informações aparecem organizadas no Quadro 1, que apresenta de maneira sistematizada nosso instrumento de avaliação.

Quadro 1 - Elementos constituintes do Instrumento de Avaliação do Nível Competitivo para Esportes de Jovens

\begin{tabular}{|c|c|c|c|c|}
\hline Categoria & Subcategoria & Critérios de Avaliação de Nível Competitivo & Score & Base Teórica \\
\hline \multirow{8}{*}{$\begin{array}{l}\text { Oferta de } \\
\text { competições }\end{array}$} & \multirow{4}{*}{$\begin{array}{l}\text { Número de } \\
\text { temporadas } \\
\text { anuais }\end{array}$} & Encontros em formato de festival de um dia & 1 & \multirow{4}{*}{$\begin{array}{l}\text { Côté e Hancock } \\
\text { (2016); } \\
\text { (Wiersma, 2005) }\end{array}$} \\
\hline & & $\begin{array}{l}\text { Três a quatro temporadas anuais de } 3 \text { ou } 4 \\
\text { meses }\end{array}$ & 2 & \\
\hline & & Duas temporadas anuais de até 6 meses & 3 & \\
\hline & & Uma só temporada anual de mais de 6 meses & 4 & \\
\hline & \multirow{4}{*}{$\begin{array}{l}\text { Modelo } \\
\text { competitivo }\end{array}$} & $\begin{array}{l}\text { Possibilidade de jogarem todos contra todos } \\
\text { várias vezes ao longo da temporada }\end{array}$ & 1 & \multirow{4}{*}{ Wiersma (2005) } \\
\hline & & $\begin{array}{l}\text { Possibilidade de jogarem todos contra todos } \\
\text { uma só vez na temporada }\end{array}$ & 2 & \\
\hline & & $\begin{array}{l}\text { Após fase classificatória, realização de fase } \\
\text { eliminatória, porém, permitindo que as equipes } \\
\text { derrotadas continuem jogando garantindo } \\
\text { número igual de partidas }\end{array}$ & 3 & \\
\hline & & $\begin{array}{l}\text { Após fase classificatória, realização de } \\
\text { eliminatória simples com permanência apenas } \\
\text { dos vitoriosos nas fases seguintes }\end{array}$ & 4 & \\
\hline
\end{tabular}


...continuação do quadro 1.

\begin{tabular}{|c|c|c|c|c|}
\hline \multirow{4}{*}{$\begin{array}{l}\text { Participação } \\
\text { dos atletas na } \\
\text { competição }\end{array}$} & \multirow{4}{*}{-} & $\begin{array}{l}\text { Regulamento prevê distribuição equilibrada dos } \\
\text { mais talentosos entre as equipes, as quais não } \\
\text { terão jogadores reservas }\end{array}$ & 1 & \multirow{4}{*}{$\begin{array}{l}\text { Burton, } \\
\text { Gillham e } \\
\text { Hammermeister } \\
\text { (2011); Wiersma } \\
\text { (2005) }\end{array}$} \\
\hline & & $\begin{array}{l}\text { Regulamento prevê divisão equilibrada de } \\
\text { tempo de participação entre titulares e reservas }\end{array}$ & 2 & \\
\hline & & $\begin{array}{l}\text { Regulamento prevê substituições obrigatórias, } \\
\text { sem se preocupar em atingir a quantidade total } \\
\text { de jogadores reservas }\end{array}$ & 3 & \\
\hline & & $\begin{array}{l}\text { Regulamento não prevê substituições } \\
\text { obrigatórias }\end{array}$ & 4 & \\
\hline \multirow{8}{*}{$\begin{array}{l}\text { Compromisso } \\
\text { esperado } \\
\text { (opinião dos } \\
\text { treinadores } \\
\text { a partir de } \\
\text { questionário } \\
\text { em escala } \\
\text { Likert) }\end{array}$} & \multirow{4}{*}{$\begin{array}{l}\text { Possibilidade } \\
\text { de participação } \\
\text { em atividades } \\
\text { esportivas } \\
\text { diversificadas }\end{array}$} & $\begin{array}{l}\text { Nenhuma restrição, permitindo ausências - } \\
\text { valor médio até } 1,0\end{array}$ & 1 & \multirow{4}{*}{$\begin{array}{l}\text { Côté (1999); } \\
\text { Wiersma (2005) }\end{array}$} \\
\hline & & $\begin{array}{l}\text { Sem restrição, permitindo equilíbrio em tempo } \\
\text { de dedicação ao handebol e outros esportes - } \\
\text { valor médio entre } 1,1 \text { e } 2,0\end{array}$ & 2 & \\
\hline & & $\begin{array}{l}\text { Sem restrição, mas com maior dedicação de } \\
\text { tempo orientado ao handebol - valor médio } \\
\text { entre } 2,1 \text { e } 3\end{array}$ & 3 & \\
\hline & & $\begin{array}{l}\text { Dedicação exclusiva ao handebol - valor } \\
\text { médio entre } 3,1 \text { e } 4,0\end{array}$ & 4 & \\
\hline & \multirow{4}{*}{$\begin{array}{l}\text { Tempo } \\
\text { semanal de } \\
\text { dedicação }\end{array}$} & Até 2 horas semanais & 1 & \multirow{4}{*}{$\begin{array}{l}\text { Côté (1999); } \\
\text { Wiersma (2005) }\end{array}$} \\
\hline & & Entre 2,1 e 4 horas semanais & 2 & \\
\hline & & Entre 4,1 e 8 horas semanais & 3 & \\
\hline & & $>8$ horas semanais & 4 & \\
\hline \multirow{4}{*}{$\begin{array}{l}\text { Distância } \\
\text { percorrida } \\
\text { para jogar* }\end{array}$} & \multirow{4}{*}{-} & $\begin{array}{l}\text { Distância média percorrida por jogo de até } 20 \\
\text { km - competição de abrangência local }\end{array}$ & 1 & \multirow{4}{*}{$\begin{array}{l}\text { Côté e Hancock } \\
\text { (2016); Wiersma } \\
(2005)\end{array}$} \\
\hline & & $\begin{array}{l}\text { Distância média percorrida por jogo entre } 20,1 \\
\text { km e } 60 \text { km - competição de abrangência } \\
\text { regional }\end{array}$ & 2 & \\
\hline & & $\begin{array}{l}\text { Distância média percorrida por jogo entre } 60,1 \\
\text { e } 100 \text { km - competição de abrangência inter- } \\
\text { regional }\end{array}$ & 3 & \\
\hline & & $\begin{array}{l}\text { Distância média percorrida por jogo superior } \\
\text { a 100,1 km - competição de abrangência } \\
\text { estadual }\end{array}$ & 4 & \\
\hline
\end{tabular}

* Os índices não possuem valores de referência na literatura, por isso foram obtidos pela média das distâncias percorridas por cada equipe em função do número de jogos por rodada a partir da análise documental das referidas competições.

Fonte: Os próprios autores

\section{IMPLICAÇÕES PRÁTICAS}

Em busca de apresentar a aplicação do instrumento de avaliação elaborado, apresentaremos agora um exemplo de sua utilização, tendo como foco três competições de handebol de jovens realizadas no estado de São Paulo: Liga de Handebol do Estado de São Paulo (LHESP), sub-12 e sub-14; Federação Paulista de Handebol (FPHB), sub-12 e sub-14; e Liga de Desenvolvimento do Handebol Paulista (LDHP), sub-13.

Em relação a "Número de Temporadas Competitivas", "Modelo Competitivo", "Participação dos atletas na competição" e "Distância percorrida para jogar", nos utilizamos das informações contidas nos regulamentos, tabelas de jogos e listas com endereços das sedes dos jogos obtidos em sites oficiais de cada entidade. Utilizamos apenas as informações de domínio público, conforme orientações de Cunha, Yokomizo e Bonacim (2014), e, devido à possível não linearidade de 
documentos oriundos de fontes online (FLICK, 2010), validamos as informações documentais com auxílio de dez treinadores de handebol de jovens que participaram destas competições, os quais, após assinarem o Termo de Consentimento Livre Esclarecido, responderam ao questionário relativo à categoria "Compromisso esperado" prevista no instrumento de avaliação elaborado.

Em relação às temporadas competitivas, os resultados indicam que para aFPHB ea LHESP sub-12 e sub-14 as temporadas são predominantemente únicas ao longo do ano, que o modelo competitivo prioriza a realização de fases classificatórias, seguidas de uma fase eliminatória. As competições sub-12 da FPHB e da LHESP e sub-14 da LHESP agrupam as equipes em divisões após a primeira fase, permitindo que a fase final seja realizada em divisões ouro, prata e bronze, que possibilitam a disputa das equipes em níveis mais ajustados das posições de $1^{\circ}$ a $4^{\circ}, 5^{\circ}$ a $8^{\circ}, 9^{\circ}$ a $12^{\circ}$ colocados etc. Isso possibilita às equipes que seriam desclassificadas que realizem a mesma quantidade de jogos que as equipes mais bem classificadas. Para a LDHP, predomina 0 modelo de festivais de um dia, no qual as equipes jogam todas contra todas em turno único, sem a realização de uma fase eliminatória ou mesmo jogo final.

Notamos resistência das competições FPHB e LHESP em relação a regras que estimulem a participação dos jovens atletas na partida, deixando a escolha pelas substituições ao encargo dos treinadores. Já a competição LDHP determina em seu regulamento que a partida seja dividida em três tempos, sendo os dois primeiros tempos a competição principal e o terceiro tempo denominado "Copa Revelação", na qual os sete jogadores com menor tempo de participação em quadra nos dois primeiros períodos são privilegiados com a oportunidade de jogar, caracterizando esta como uma regra que se aproxima da divisão dos tempos de participação dos atletas de maneira o mais equilibrada possível.

A FPHB sub-14 e a LHESP sub-12 e sub-14 se comportaram como competições regionais e inter-regionais, com abrangência média maior que 60,1 km e inferior a $100 \mathrm{~km}$ entre as sedes dos jogos, embora o desvio padrão aponte para as competições sub-14 da LHESP e da FPHB a possibilidade de que viagens para realização de um jogo superem $100 \mathrm{~km}$ de distância. No caso da competição sub-12 da FPHB, a baixa distância média para cada jogo, que caracterizou esta como uma competição regional, foi conquistada pelo formato de rodada dupla, na qual a criança viaja para uma das sedes participantes e realiza dois jogos no mesmo dia, possibilitando que, mesmo para viagens mais longas, a criança tenha a possibilidade de jogar mais. A LDHP, por ser em formato de festival, foi a competição com menor quilometragem percorrida para cada jogo, caracterizando-a como uma competição local. Isso foi determinado pela centralidade de sua sede em relação às equipes participantes e pelo fato de que, segundo as tabelas de jogo verificadas, as equipes puderam fazer entre três e cinco jogos durante o dia do evento.

Quanto ao compromisso e tempo de dedicação esperados pelos treinadores para participar das competições, verificamos uma variação de três a nove horas semanais, com relato de até cinco treinos por semana para uma equipe sub-12 em disputa da competição desta faixa etária da FPHB. Para a FPHB sub-12 e a LHESP sub-12 e sub-14 os treinadores não restringem a participação em outras atividades, desde que a maior dedicação seja dada ao handebol; para a FPHB sub-14 observamos maior tendência à especialização exclusiva no handebol; e para a LDHP, embora com valor inferior se comparado às outras competições, os treinadores também tendem a exigir de maneira geral que seu atletas dediquem-se mais o handebol se comparado a outras atividades esportivas.

A Tabela 1 apresenta como se enquadram as competições analisadas. 


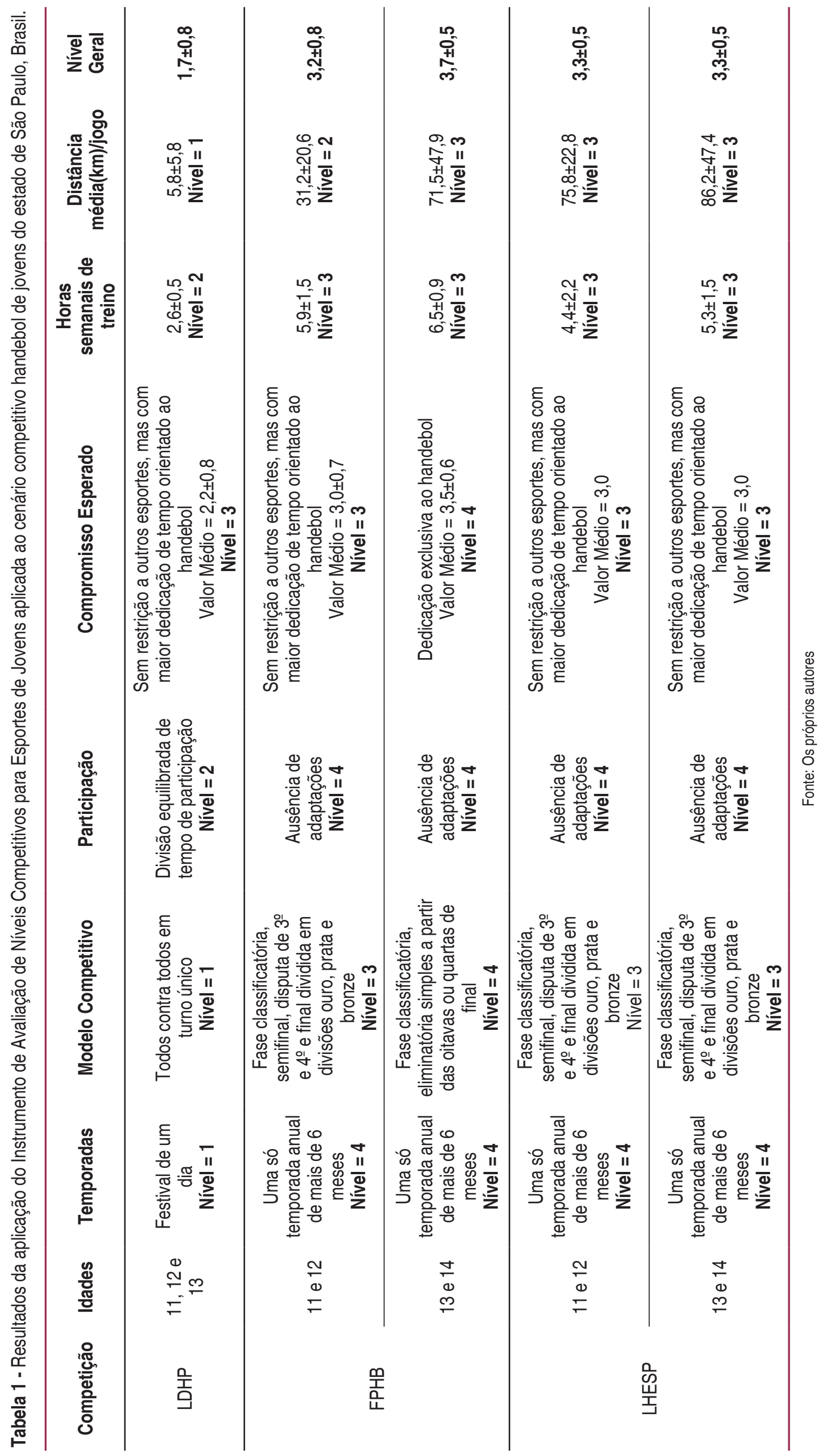


Diante dessas informações, os resultados apontam que a LDHP é uma competição cujo formato de organização permite enquadrá-la como uma competição de nível um, mas que transita para o nível dois, logo, atendendo às demandas de uma competição organizada para a faixa etária dos 11 aos 13 anos em respeito ao desenvolvimento competitivo dos jovens inseridos nessas competições, sobretudo, pela oferta de temporadas competitivas mais curtas, pontuais e centralizadas numa mesma sede, atendendo a demandas mais locais (CÔTÉ, 1999; CÔTÉ; HANCOCK, 2016; WIERSMA, 2005).

Embora a FPHB e a LHESP sejam elaboradas para crianças entre 11 e 14 anos de idade, as quais ainda não devem ser especializadas em um só esporte (CÔTÉ, 1999), percebemos, em relação à quantidade de temporadas, participação, distância percorrida para participação em uma partida e compromisso esperado para participação, níveis competitivos que transitam entre 0 três e o quarto, enquadrando essas competições como altamente orientadas à competitividade, exigindo grande compromisso e dedicação anual, tendo como finalidade buscar altos níveis de realização na prática esportiva (WIERSMA, 2005). Segundo Wiersma (2005), esse modelo competitivo passa a exigir maior intensidade no treino e nas demandas associadas à competição, exigindo que o atleta tenha níveis elevados de habilidade e experiência esportiva, prontidão física e emocional, aspectos que não deveriam ser fomentados e esperados em idades ainda tão precoces. Essa perspectiva é contraditória às orientações de Engebretsen et al. (2010) e Bergeron et al. (2015), de modo que tais demandas possam incorrer no risco de lesões, abandono precoce e influência de que oportunidades competitivas sejam ofertadas por motivos de desenvolvimento maturacional precoce.

Acerca das oportunidades de prática, em estudo realizado numa competição de handebol orientada exclusivamente para jovens do sexo masculino de até 13 anos de idade, Leonardo et al. (2018) encontraram exatamente essa tendência, ao constatarem que treinadores são levados a oportunizar maior quantidade de tempo efetivo em quadra aos atletas mais velhos dentro da idade-alvo da competição, evidenciando que o efeito da idade relativa, que tem relação direta com os efeitos da maturação precoce, pode ser determinante para que jogar sejam uma oportunidade para poucos, estimulando o abandono na prática do handebol.

Além disso, Côté (1999) considera este o período de transição entre a fase da experimentação para o início da especialização, considerando que apenas a partir dos 13 anos de idade é que a maior ênfase deva ser dada a uma só modalidade, embora, com estímulo à manutenção na prática de outro esporte. $\mathrm{O}$ alto grau de competitividade típico das competições que transitam para o nível quatro passam a determinar a necessidade de maior aprofundamento para participação nas competições, fazendo com que a escolha de um só esporte seja uma tendência (WIERSMA, 2005).

Percebemos que apesar das competições LHESP e FPHB se orientarem mais para a competitividade e a LDHP parecer mais ajustada às características de aprendizagem, os resultados avaliativos inerentes às percepções dos treinadores, no tocante ao compromisso esperado que seus atletas tenham com a prática do handebol, demonstram que os treinadores entendem a preparação para essas competições apoiados numa perspectiva que tende à especialização dos jovens na prática do handebol, inadequada à faixa etária (CÔTÉ, 1999).

Esse desalinhamento entre as metas competitivas esperadas para o público jovem, especialmente no caso da LDHP, que apresenta pressupostos que demonstram maior orientação para a aprendizagem em seu modelo organizativo, e a expectativa fomentada pelo 
treinador podem resultar em condutas incoerentes desses treinadores ao ambiente competitivo em seu sentido pedagógico e de engajamento.

Essas atitudes podem se manifestar como ênfase exacerbada na conquista e na vitória (WIERSMA, 2005), evidências que demonstram a importância de as metas de uma competição serem compreendidas de antemão, uma vez que condutas dos treinadores podem subverter 0 ambiente competitivo por meio de atitudes transgressoras, mesmo que esses ambientes sejam previamente designados por metas de aprendizagem e desenvolvimento de competências (BURTON; GILLHAM; HAMMERMEISTER, 2011; PALOU et al., 2013; SIEGENTHALER; GONZALEZ, 1997).

\section{CONSIDERAÇÕES FINAIS}

O presente estudo tem por esforço apresentar categorias que possam balizar um instrumento de avaliação do nível competitivo, tendo em vista as necessidades que 0 ambiente competitivo de jovens demanda, em termos de sustentar-se como um ambiente destinado ao contínuo processo de ensino, vivência e aprendizagem esportiva.

Para isso, sustentados em estruturas teóricas que apresentam evidências e informações acerca do ambiente competitivo de jovens, elaboramos quatro categorias, cada uma com subcategorias e critérios de avaliação que permitem classificar a competição em quatro níveis distintos, sendo o nível um dotado de características de pouca competitividade e maior diversidade na prática esportiva e o nível quatro altamente relacionado à presença de competitividade e especialização na prática esportiva.

Para exemplificar a aplicação desse instrumento, nos valemos de informações oriundas de documentos disponíveis na internet de três competições de handebol de grande abrangência no estado de São Paulo e opiniões oriundas de um questionário aplicado com dez treinadores, permitindo-nos avaliar o grau de adequação das competições analisadas. Constatamos que a LHESP e a FPHB possuem características que as afastam de propostas adequadas ao público jovem e que a LDHP possui características que a configuram como uma competição mais ajustada às metas pedagógicas e de aprendizagem diante da prática competitiva.

Destacam-se entre os resultados obtidos a percepção dos treinadores acerca do compromisso esperado por eles em relação aos seus jovens atletas. Independentemente das competições terem maior ou menor orientação às necessidades dos jovens, conforme apontado pelo quadro teórico que sustenta este estudo, percebemos uma forte expectativa dos treinadores para um grande compromisso de seus atletas com o handebol, evidenciando uma tendência de especialização na prática dessa modalidade, que pode resultar em altas demandas de exigência em idades precoces e na possível subversão por parte dos treinadores em relação às metas de aprendizagem inerentes a ambientes competitivos modificados em consonância com as necessidades de um público tão jovem, que se encontra entre 11 e 14 anos.

Por fim, por serem essas fontes de informação tradicionais em competições de um modo geral, entendemos que o instrumento definido nesta investigação pode ser também aplicado a outras modalidades esportivas. 


\section{REFERÊNCIAS}

BARDIN, Laurence. Análise de conteúdo. São Paulo: Edições 70, 2016.

BERGERON, Michael F. et al. International Olympic Committee consensus statement on youth athletic development. British Journal of Sports Medicine, v. 49, n. 13, p. 843-851, 2015.

BURTON, Damon; GILLHAM, Andrew D.; HAMMERMEISTER, Jon. Competitive engineering: Structural climate modifications to enhance youth athletes' competitive experience. International Journal of Sports Science \& Coaching, v. 6, n. 2, p. 201-217, 2011.

CAVICCHIOLI NETO, Virgilio et al. Desenvolvimento e integração de mapas dinâmicos georreferenciados para o gerenciamento e vigilância em saúde. Journal of Health Informatics, v. 6 , n. 1, p. 3-9, 2014.

CHOI, Hong Suk; JOHNSON, Britton; KIM, Young K. Children's development through sports competition: Derivative, adjustive, generative, and maladaptive approaches. Quest, v. 66, n. 2, p. 191 202, 2014.

CÔTÉ, Jean. The influence of the family in the development of talent in sport. The Sport Psychologist, v. 13, n. 4, p. 395-417, 1999.

CÔTÉ, Jean; LIDOR, Ronnie; HACKFORT, Dieter. ISSP position stand: to sample or to specialize? Seven postulates about youth sport activities that lead to continued participation and elite performance. International Journal of Sports Exercise and Psychology, v.9, p. 7-17, 2009.

CÔTÉ, Jean; BAKER, Joe; ABERNETHY, Bruce. Practice and play in the development of sport expertise. Handbook of Sport Psychology, v. 3, p. 184-202, 2007.

CÔTÉ, Jean.; HANCOCK, D. J. Evidence-based policies for youth sport programmes. International Journal of Sport Policy and Politics, v. 8, n. 1, p. 51-65, 2016.

CRANE, Jeff; TEMPLE, Viviene. A systematic review of dropout from organized sport among children and youth. European Physical Education Review, v. 21, n. 1, p. 114-131, 2015.

CUNHA, Júlio Araújo Carneiro da; YOKOMIZO, Cesar Akira; BONACIM, Carlos Alberto Grespan. Miopias de uma lente de aumento: as limitações da análise de documentos no estudo das organizações. Revista Alcance, v. 20, n. 4, p. 431-446, 2014.

DREWE, Sheryle Bergmann. Competing conceptions of competition: Implications for physical education. European Physical Education Review, v. 4, n. 1, p. 5-20, 1998.

ENGEBRETSEN, Lars et al. The International Olympic Committee Consensus Statement on age determination in high-level young athletes. British Journal of Sports Medicine, v. 44, n. 7, p. 476484, 2010.

FLICK, Uwe. An introduction to qualitative research. London: Sage, 2010.

FRASER-THOMAS, Jessica; CÔTÉ, Jean. Youth sports: Implementing findings and moving forward with research. Athletic Insight, v. 8, n. 3, p. 12-27, 2006.

GONÇALVES, Carlos Eduardo; CARVALHO, Humberto M.; LIGHT, Richard. Keeping women in sport: positive experiences of six women's experiences growing up and staying with sport in Portugal. Asian Journal of Exercise \& Sports Science, v. 8, n. 1, p. 39-52, 2011. 
LEONARDO, Lucas; GALATTI, Larissa Rafaela; SCAGLIA, Alcides José. Disposições preliminares sobre um modelo de participação competitiva para jovens e o papel do treinador. In: GONZALEZ, Ricardo Hugo; MACHADO, Márcia Maria Tavares (Org.). Pedagogia do esporte: novas tendências. Fortaleza: Universidade Federal do Ceará, 2017. p. 301-324.

LEONARDO, Lucas et al. $O$ efeito da idade relativa influencia o tempo de participação competitiva de atletas de handebol do sexo masculino com até 13 anos de idade. Retos, v. 33, p. 195-198, 2018.

LLOYD, Rhodri S.; OLIVER, Jon L. The youth physical development model: A new approach to longterm athletic development. Strength \& Conditioning Journal, v. 34, n. 3, p. 61-72, 2012.

MOUNTJOY, Margo et al. IOC consensus statement:"training the elite child athlete". British Journal of Sports Medicine, v. 42, n. 3, p. 163-164, 2008.

PALOU, Pere et al. Acceptance of gamesmanship and cheating in young competitive athletes in relation to the motivacional climate generated by parents and coaches. Perceptual of Motor Skills, v. 17, n. 1, p. 1-14, 2013.

REVERDITO, Riller Silva et al. Competições escolares: reflexão e ação em pedagogia do esporte para fazer a diferença na escola. Pensar a Prática, v. 11, n. 1, p.37-45, 2008.

SCAGLIA, Alcides José et al. 0 ensino dos jogos esportivos coletivos: as competências essenciais e a lógica do jogo em meio ao processo de organizacional sistêmico. Movimento, v. 19, n. 4, p. 227-249, 2013.

SIEGENTHALER, Kim; GONZALEZ, G. Leticia. Youth sports as serious leisure a critique. Journal of Sport \& Social Issues, v. 21, n. 3, p. 298-314, 1997.

WIERSMA, Lenny D. Reformation or reclassification? A proposal of a rating system for youth sport programs. Quest, v. 57, n. 4, p. 376-391, 2005.

YIN, Robert K. Pesquisa qualitativa do início ao fim. Porto Alegre: Penso, 2016. 
